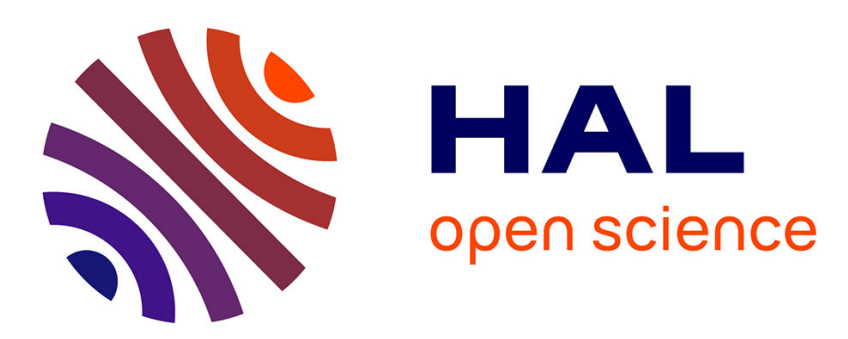

\title{
An alternative approach of valence advantage in spatial competition
}

\author{
Guillaume Hollard, Stéphane Rossignol
}

\section{To cite this version:}

Guillaume Hollard, Stéphane Rossignol. An alternative approach of valence advantage in spatial competition. Journal of Public Economic Theory, 2008, 10 (3), pp.441-454. 10.1111/j.14679779.2008.00371.x . hal-00267218

\section{HAL Id: hal-00267218 \\ https://hal.science/hal-00267218}

Submitted on 27 Mar 2008

HAL is a multi-disciplinary open access archive for the deposit and dissemination of scientific research documents, whether they are published or not. The documents may come from teaching and research institutions in France or abroad, or from public or private research centers.
L'archive ouverte pluridisciplinaire HAL, est destinée au dépôt et à la diffusion de documents scientifiques de niveau recherche, publiés ou non, émanant des établissements d'enseignement et de recherche français ou étrangers, des laboratoires publics ou privés. 


\title{
An alternative approach to valence advantage in spatial competition.*
}

\author{
Guillaume Hollard \\ CNRS, Université de Paris 1 \\ and \\ Stéphane Rossignol \\ Université de Paris 1 and Université de Versailles
}

October 5, 2007

\begin{abstract}
This paper explores a two-candidate spatial voting model, where one candidate has a valence advantage. Contrary to previous models, we introduce a multiplicative advantage, rather than an additive one. This takes into account the possible interaction between the quality of a candidate and his policy platform. This leads to a strikingly different model, in which all extreme voters support the favored candidate.
\end{abstract}

- Keywords: Spatial voting, Valence advantage

- J.E.L. Classification: D72, D71

${ }^{*}$ Guillaume Hollard, CNRS, Université Paris 1, 106-112 boulevard de l'Hopital, 75647 Paris Cedex 13, France (Guillaume.Hollard@univ-paris1.fr). Stéphane Rossignol, Université Paris 1 and Université de Versailles, batiment Fermat, 45 avenue des USA, 78035 Versailles Cedex (rossignol@math.uvsq.fr). The authors would like to thank P. De Donder, B. Grofman, M. Le Breton, A. Kirman, J.F. Laslier, S. Martin, H. Moulin, J. Roemer and K. Van der Straeten for helpful comments. The usual disclaimer applies. 


\section{Introduction.}

The Downsian model constitutes a benchmark for the analysis of electoral competition. It predicts a close race between the two candidates and minimal differentiation in chosen platforms at equilibrium (Downs, 1957). At equilibrium, both parties or candidates choose the median platform. However, the empirical analysis of elections shows that differentiation exists ${ }^{1}$. To explain this fact, a first line of research introduces uncertainty in the position of the median voter (i.e. candidates have imperfect information on the voters' positions) as well as partisan preferences (i.e. candidates care not only about winning but also about defending a particular program $)^{2}$. Adding both uncertainty and partisan preferences for the candidates allows us to predict differentiation at equilibrium.

An alternative line of research examines the impact of removing the hypothesis of symmetric candidates. Candidates can be differently evaluated, even if they adopt the same policy positions. Voters then evaluate the candidates not only on the "policy issues", but also according to characteristics that are unanimously positively or negatively evaluated. For example, all agents prefer candidates who are not corrupt, have more charisma, greater intelligence, superior character, or better handshaking skills. Stokes (1963) was the first to underline the importance of those non spatial aspects. He called them "valence issues" ${ }^{3}$. It is rather intuitive that the candidate with a valence disadvantage will lose the election if he chooses a platform identical to his opponent's. He thus has a clear incentive to choose a different platform. Valence advantages then account for differentiation in the spatial model.

The literature on valence-issues has grown significantly in the last decade offering a better understanding of the strategic consequences of the introduction of a

\footnotetext{
${ }^{1}$ See Poole and Rosenthal, 1984.

${ }^{2}$ Among others, see Wittman, 1977 and 1990, and Osborne 1995 for a survey

${ }^{3}$ The origin of the term "valence" deserves comment. Stokes indicates that he borrowed the term from the German psychologist Kurt Lewin. In psychology indeed, valence refers to the attraction or repulsion for an object. Note that psychology itself borrowed this notion from chemistry, where valence measures the potential number of chemical links of an atom.
} 
valence advantage (Groseclose(2001), Schofield (2003), Aragones and Palfrey(2002), Ansolabehere and Snyder(2000), Dix and Santore (2002) among others). Recent contributions proposed more sophisticated models, that help understanding the origins of valence advantages. A valence advantage could arise from a greater capacity to commit to a precise platform (Egan 2007), party support (Wiseman 2006) or campaign spending (Herrera et al. 2007, Ashworth and Bueno de Mesquita 2007). Explicitly modeling the process of valence formation allows us to extend the Downsian framework to take into account an endogenous determination of valence advantages. Candidates can choose a level of effort that (stochastically) increase their valence (Carrilo and Castanheira, 2002 and 2006 and Meirowitz 2006), a level of campaign spending (Erikson and Palfrey 2000, Sahuget and Persico 2006, Zakharov 2005).

A common feature to these models is to assume that the utility of a voter increases by a fixed amount when he considers the position of the favored candidate i.e. valence advantage results in adding a constant amount of utility. Such an additive valence-advantage means that the utility is separable, i.e. that valence-issues have no link with the policy issues. This hypothesis is clearly quite restrictive, since we can validly think that candidates' qualities can interact with the evaluation by the agents of their policy positions. The degree of corruption of a candidate matters more if he proposes a high level of public spending. This justifies a multiplicative form for the valence-advantage.

This paper investigates the consequences of moving from an additive form to a multiplicative form. The main result proves that the less favored candidate is supported by voters whose preferred platform is in an unbounded set in the additive case, but a bounded set in the multiplicative one. It is important to note that our result holds for any dimension of the policy space (while it is often assumed that the policy space is of dimension 1), and any distance (while much of the literature is restricted to the Euclidean distance).

A direct and striking consequence of this result for dimension 1 is that the electorates of both sides on the equilibrium spectrum support the most favored 
candidate. We get an "ends against the middle" split of the population. This is in sharp contrast with the additive case which predicts a split into two intervals. This result holds for the higher dimensions. For example in dimension 2, voters supporting the less favored candidates are located within a ball. This offers a new explanation for situations in which a candidate, or alternative, is supported by extreme voters from both the left and the right.

As in the additive case, the favored candidate is guaranteed to win the election if his valence advantage is above a threshold. No equilibrium in pure strategy exists if the valence advantage is below that threshold.

The paper is organized as follows : Section 2 presents the model and main assumptions and Section 3 presents the main results. We conclude in Section 4.

\section{The model}

A voter $i$ is identified with his preferred platform, or bliss point, $a_{i}$ in the policy space $\mathbb{R}^{n}$. A candidate $j$ chooses a policy platform $x_{j} \in \mathbb{R}^{n}$. In the basic spatial model of electoral competition, a voter $i$ votes for candidate $j$ whose announced platform $x_{j}$ is the closest to $a_{i}$. If candidate $j$ is elected, the utility function of voter $i$ is:

$$
u\left(x_{j}, a_{i}\right)=-\left\|x_{j}-a_{i}\right\| .
$$

When valence advantages are introduced, each candidate has an intrinsic quality independent of the chosen platform. An additional parameter $\theta_{j}>0$ thus accounts for candidate $j$ valence. The higher $\theta_{j}$, the more appreciated candidate $j$.

When the valence advantage is modeled by adding a constant, the utility is written as the following:

$$
u^{a d}\left(\theta_{j}, x_{j}, a_{i}\right)=-\left\|x_{j}-a_{i}\right\|+\theta_{j}
$$

As explained, we introduce a multiplicative valence advantage. The utility function is now written: 


$$
u\left(\theta_{j}, x_{j}, a_{i}\right)=-\frac{1}{\theta_{j}}\left\|x_{j}-a_{i}\right\|
$$

Note that $x \mapsto\|x\|$ is any norm on $\mathbb{R}^{n}$. Most of our results don't depend on the choice of the norm. We define $k=\frac{\theta_{1}}{\theta_{2}}$ and assume, without loss of generality, that $0<\theta_{2}<\theta_{1}$, i.e. $k>1$. Then candidate 1 gets a clear advantage.

Once candidates have announced their platforms $x_{1}$ and $x_{2}$, the electorate splits in three parts $\Omega_{1}\left(x_{1}, x_{2}, k\right), \Omega_{2}\left(x_{1}, x_{2}, k\right)$ and $I\left(x_{1}, x_{2}, k\right) . \Omega_{i}$ is the set of voters who support candidate $i$ and $I$ is the set of voters who are indifferent between the two candidates. Formally, we have:

$$
\begin{aligned}
\Omega_{1}\left(x_{1}, x_{2}, k\right) & =\left\{a \in \mathbb{R}^{n} ; \frac{1}{\theta_{1}}\left\|x_{1}-a\right\|<\frac{1}{\theta_{2}}\left\|x_{2}-a\right\|\right\} \\
& =\left\{a \in \mathbb{R}^{n} ;\left\|x_{1}-a\right\|<k\left\|x_{2}-a\right\|\right\} \\
\Omega_{2}\left(x_{1}, x_{2}, k\right) & =\left\{a \in \mathbb{R}^{n} ; \frac{1}{\theta_{2}}\left\|x_{2}-a\right\|<\frac{1}{\theta_{1}}\left\|x_{1}-a\right\|\right\} \\
& =\left\{a \in \mathbb{R}^{n} ; k\left\|x_{2}-a\right\|<\left\|x_{1}-a\right\|\right\} \\
I\left(x_{1}, x_{2}, k\right) & =\left\{a \in \mathbb{R}^{n} ; k\left\|x_{2}-a\right\|=\left\|x_{1}-a\right\|\right\}
\end{aligned}
$$

Voters, i.e. bliss points, are distributed on $\mathbb{R}^{n}$, according to a density distribution function $f$. The function $f$ is assumed to be bounded on $\mathbb{R}^{n}$, and we denote by $X$ the support of $f$, i.e. $f(x)=0$ for $x \notin X$. The proportion of voters who prefer candidate $j$ to his opponent is then given by the function $S_{j}\left(x_{1}, x_{2}, k\right)$, where:

$$
S_{j}\left(x_{1}, x_{2}, k\right)=\int_{\Omega_{j}} f(a) d a .
$$

Note that the set $I=I\left(x_{1}, x_{2}, k\right)$ is of negligible importance, i.e. $\int_{I} f(a) d a=0$.

In the additive case, we replace $u\left(\theta_{j}, x_{j}, a_{i}\right)$ by $u^{a d}\left(\theta_{j}, x_{j}, a_{i}\right)=-\left\|x_{j}-a_{i}\right\|+\theta_{j}$. We set $b=\theta_{1}-\theta_{2}>0$. We define the sets: 


$$
\Omega_{1}^{a d}\left(x_{1}, x_{2}, b\right)=\left\{a \in \mathbb{R}^{n} ;\left\|x_{1}-a\right\|<b+\left\|x_{2}-a\right\|\right\}
$$

and

$$
\Omega_{2}^{a d}\left(x_{1}, x_{2}, b\right)=\left\{a \in \mathbb{R}^{n} ;\left\|x_{1}-a\right\|>b+\left\|x_{2}-a\right\|\right\}
$$

Then, $S_{j}^{a d}\left(x_{1}, x_{2}, k\right)=\int_{\Omega_{j}^{a d}} f(a) d a$.

Since the candidates are only office-motivated, we can then assume that the utility of candidate $j$ is formally given by:

$$
v_{j}\left(x_{1}, x_{2}\right)=\left\{\begin{array}{cc}
0 & \text { if } S_{j}\left(x_{1}, x_{2}, k\right)<1 / 2 \\
\frac{1}{2} & \text { if } S_{j}\left(x_{1}, x_{2}, k\right)=1 / 2 \\
1 & \text { if } S_{j}\left(x_{1}, x_{2}, k\right)>1 / 2
\end{array}\right.
$$

The game of asymmetric electoral competition is played sequentially and its main elements are summarized by the couple $(k, f)$. The chronology of the game is the following: first the two candidates announce their platforms $x_{1}$ and $x_{2}$; secondly the electors vote for their preferred candidate. In the next section, we solve the game sequentially.

\section{Main results}

We first explore the electorate's split both in the additive and multiplicative cases, when the candidates have already announced their platforms. The first step of the game of asymmetric electoral competition, i.e. the existence of equilibria, is then analyzed in the second subsection.

\subsection{The electorate's split in the additive and multiplicative cases}

The multiplicative and the additive cases mainly differ in the split of the electorate between those who support candidate 1, the advantaged candidate, and those who support candidate 2. Technically, we explore the properties of the sets $\Omega_{1}$ and $\Omega_{2}$. Our main proposition proves that a substantial difference exists for any norm and any dimension of the policy space (proposition 1). This result is particularly 
striking if we restrict to the Euclidean norm (proposition 2). We also provide an explicit comparison in the particular, but popular, case where the policy space is of dimension 1 (corollary 1).

Proposition 1 For every norm on $\mathbb{R}^{n}$, we have:

(i) The set $\Omega_{2}\left(x_{1}, x_{2}, k\right)$ is a bounded open set in $\mathbb{R}^{n}$. It is non-empty iff $x_{1} \neq x_{2}$

(ii) The set $\Omega_{2}^{a d}\left(x_{1}, x_{2}, b\right)$ is unbounded if $b<\left\|x_{2}-x_{1}\right\|$,

and empty if $b \geq\left\|x_{2}-x_{1}\right\|$.

Proof. (i) If $a \in \Omega_{2}\left(x_{1}, x_{2}, k\right)$, then

$k\left\|x_{2}-a\right\|<\left\|x_{1}-a\right\|=\left\|x_{1}-x_{2}+x_{2}-a\right\| \leq\left\|x_{1}-x_{2}\right\|+\left\|x_{2}-a\right\|$

thus $(k-1)\left\|x_{2}-a\right\|<\left\|x_{1}-x_{2}\right\|$

i.e.

$$
\text { If } a \in \Omega_{2}\left(x_{1}, x_{2}, k\right) \text {, then }\left\|x_{2}-a\right\|<\frac{1}{k-1}\left\|x_{1}-x_{2}\right\|
$$

Thus $\Omega_{2}\left(x_{1}, x_{2}, k\right)$ is a bounded set. It is clearly an open set, according to (5).

(ii) If $x_{1}=x_{2}$, then $\Omega_{2}\left(x_{1}, x_{2}, b\right)$ is clearly empty. We assume now that $x_{1} \neq x_{2}$.

We set $u=\frac{x_{2}-x_{1}}{\left\|x_{2}-x_{1}\right\|}$.

- For $a=x_{2}+\lambda u$, with $\lambda>0$, we have $\left\|x_{2}-a\right\|=\lambda$ since $\|u\|=1$. Moreover:

$$
\begin{aligned}
& \left\|x_{1}-a\right\|=\left\|x_{2}+\lambda u-x_{1}\right\|=\left\|\left(x_{2}-x_{1}\right)\left(1+\frac{\lambda}{\left\|x_{2}-x_{1}\right\|}\right)\right\|=\left\|x_{2}-x_{1}\right\|\left(1+\frac{\lambda}{\left\|x_{2}-x_{1}\right\|}\right) \\
& =\left\|x_{2}-x_{1}\right\|+\lambda \\
& \left\|x_{1}-a\right\|-\left\|x_{2}-a\right\|-b=\left\|x_{2}-x_{1}\right\|+\lambda-\lambda-b=\left\|x_{2}-x_{1}\right\|-b>0 \text { if } b<\left\|x_{2}-x_{1}\right\|
\end{aligned}
$$

Thus $\left\|x_{1}-a\right\|>\left\|x_{2}-a\right\|+b$ if $a=x_{2}+\lambda u$, for every $\lambda>0$, when $b<\left\|x_{2}-x_{1}\right\|$.

It shows that $\Omega_{2}^{a d}\left(x_{1}, x_{2}, b\right)$ is unbounded if $b<\left\|x_{2}-x_{1}\right\|$.

- When $b \geq\left\|x_{2}-x_{1}\right\|$, we have

$$
\left\|x_{1}-a\right\|=\left\|x_{1}-x_{2}+x_{2}-a\right\| \leq\left\|x_{1}-x_{2}\right\|+\left\|x_{2}-a\right\| \leq b+\left\|x_{2}-a\right\|
$$

thus $\Omega_{2}^{a d}\left(x_{1}, x_{2}, b\right)$ is empty.

Voters supporting the disadvantaged party have their bliss points included in a bounded set in the multiplicative case. Our next proposition shows how the set $\Omega_{2}\left(x_{1}, x_{2}, k\right)$ can be constructed, in the case of an Euclidean norm.

Proposition 2 With the Euclidean norm, the set $\Omega_{2}\left(x_{1}, x_{2}, k\right)$ is a hyperball in $\mathbb{R}^{n}$ centered at $c\left(x_{1}, x_{2}, k\right)=\frac{k^{2}}{k^{2}-1} x_{2}-\frac{1}{k^{2}-1} x_{1}$ of radius $r\left(x_{1}, x_{2}, k\right)=\frac{k}{k^{2}-1}\left\|x_{1}-x_{2}\right\|$. Let 
$\Delta$ denote the line $\left(x_{1}, x_{2}\right)$. The set $\Omega_{2}\left(x_{1}, x_{2}, k\right)$ is a hyperball tangent to the cone of vertex $x_{1}$, axis $\Delta$, and angle $2 \alpha$ such that $\sin \alpha=\frac{1}{k}$.

Proof See Appendix.

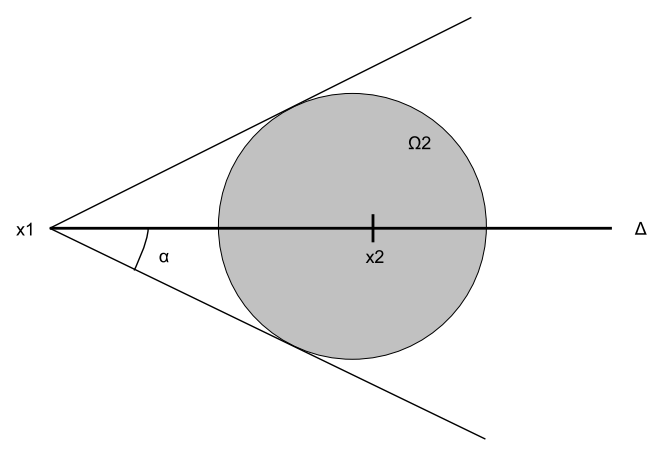

Figure 1: $\Omega_{2}\left(x_{1}, x_{2}, k\right)$

The Downsian model as the limit of the asymmetric game It is natural to ask how the model behaves when parties tend toward symmetry, i.e. when $k \rightarrow 1^{+}$. We have $\Omega_{2}=\left\{a \in X ; k\left\|x_{2}-a\right\|<\left\|x_{1}-a\right\|\right\} \longrightarrow\left\{a \in X ;\left\|x_{2}-a\right\|<\left\|x_{1}-a\right\|\right\}$, as $k \rightarrow 1^{+}$, i.e. the set $\Omega_{2}$ tends to the half-space delimited by the median hypersurface $^{4}$ between $x_{1}$ and $x_{2}$ as in the symmetrical model.

Corollary 1 In a one dimensional setting, $\left.\Omega_{2}\left(x_{1}, x_{2}, k\right)=\right] \frac{k x_{2}+x_{1}}{k+1} ; \frac{k x_{2}-x_{1}}{k-1}\left[\right.$ if $x_{1}<x_{2}$

We can observe that $\Omega_{1}=\mathbb{R} \backslash \bar{\Omega}_{2}$ is a non convex set. It is a situation of "ends against the middle". Candidate 1 gets support of voters located at both ends of the electoral spectrum (see Figure 2).

\footnotetext{
${ }^{4}$ The median hypersurface of $x_{1}$ and $x_{2}$ is the set of points in $\mathbb{R}^{n}$ that are equidistant from $x_{1}$ and $x_{2}$.
} 


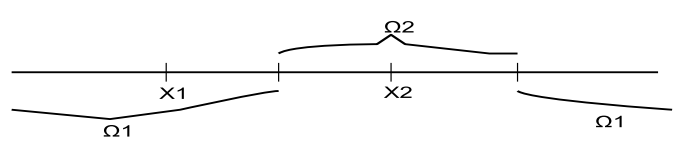

Figure 2: $\operatorname{dim} 1$

\subsection{Analysis of the game of asymmetric spatial competition}

Before analyzing the game, some further notations are required. We define the set $X_{1}^{*}$ player 1's strategies that guarantee him or her, to win the election.

$$
\begin{aligned}
X_{1}^{*} & =\left\{x_{1} \in X ; \forall x_{2} \in X, v_{1}\left(x_{1}, x_{2}, k\right)=1\right\} \\
& =\left\{x_{1} \in X ; \forall x_{2} \in X, S_{1}\left(x_{1}, x_{2}, k\right)>\frac{1}{2}\right\}
\end{aligned}
$$

We can define similarly $X_{1}^{* a d}$ in the additive case.

Proposition 3 With the Euclidean norm, if $X$ is a compact set, then $X_{1}^{*}$ is an open, convex set.

Proof. See Appendix.

We now turn to the analysis of Nash equilibria:

Proposition 4 For every norm on $\mathbb{R}^{n}$, in both multiplicative and additive cases, one of the following two assertions holds:

- The set $X_{1}^{*}$ is not empty and for any $x_{2} \in X,\left(x_{1}, x_{2}\right)$ is a Nash equilibrium if and only if $x_{1} \in X_{1}^{*}$.

- The set $X_{1}^{*}$ is empty and there exists no Nash equilibrium in pure strategy.

Proof. We have to show that $\left(x_{1}, x_{2}\right)$ is a Nash equilibrium iff $x_{1} \in X_{1}^{*}$.

If $\left(x_{1}, x_{2}\right)$ is a Nash equilibrium, then $v_{1}\left(x_{1}, x_{2}\right) \geq v_{1}\left(x_{2}, x_{2}\right)=1$, thus $v_{1}\left(x_{1}, x_{2}\right)=1$ 
Then $0=v_{2}\left(x_{1}, x_{2}\right) \geq v_{2}\left(x_{1}, x_{2}^{\prime}\right)$ for all $x_{2}^{\prime} \in X$

As $v_{1}=1-v_{2}$, it means that

$1=v_{1}\left(x_{1}, x_{2}\right) \leq v_{1}\left(x_{1}, x_{2}^{\prime}\right)$ for all $x_{2}^{\prime} \in X$

i.e. $v_{1}\left(x_{1}, x_{2}^{\prime}\right)=1$ for all $x_{2}^{\prime} \in X$

i.e. $x_{1} \in X_{1}^{*}$.

Conversely, if $x_{1} \in X_{1}^{*}$ and $x_{2} \in X$, we have

$v_{1}\left(x_{1}, x_{2}\right)=1 \geq v_{1}\left(x_{1}^{\prime}, x_{2}\right)$ for all $x_{1}^{\prime} \in X$

$v_{2}\left(x_{1}, x_{2}\right)=0 \geq v_{2}\left(x_{1}, x_{2}^{\prime}\right)$ for all $x_{2}^{\prime} \in X$

which proves that $\left(x_{1}, x_{2}\right)$ is a Nash equilibrium.

Proposition 5 For every continuous distribution function $f$ on the set $X$, there exist positive numbers $k^{*}(f), k^{* *}(f)$, with $1 \leq k^{*}(f) \leq k^{* *}(f)$ and $k^{*}(f)<+\infty$ such that:

(i) $X_{1}^{*}(k)=\varnothing$ if $k<k^{*}(f)$

(ii) $X_{1}^{*}(k) \neq \varnothing$ and $X_{1}^{*}(k) \neq X$ if $k^{*}(f)<k<k^{* *}(f)$

(iii) $X_{1}^{*}(k)=X$ if $k>k^{* *}(f)$.

Moreover, $k^{* *}(f)<+\infty$ if and only if $X$ is bounded.

Proof - Assume that $0<k<k^{\prime}$.

If $a \in \Omega_{2}\left(x_{1}, x_{2}, k^{\prime}\right)$ then

$$
\left\|x_{1}-a\right\|>k^{\prime}\left\|x_{2}-a\right\| \geq k\left\|x_{2}-a\right\|
$$

thus

$$
a \in \Omega_{2}\left(x_{1}, x_{2}, k\right)
$$

Hence if $k<k^{\prime}$, then $\Omega_{2}\left(x_{1}, x_{2}, k^{\prime}\right) \subseteq \Omega_{2}\left(x_{1}, x_{2}, k\right)$

Since $X_{1}^{*}(k)=\left\{x_{1} \in X ; \int_{\Omega_{2}\left(x_{1}, x_{2}, k\right)} f(a) d a<\frac{1}{2}, \forall x_{2} \in X\right\}$

then $k<k^{\prime} \Rightarrow X_{1}^{*}(k) \subseteq X_{1}^{*}\left(k^{\prime}\right)$

For $0<k<1, X_{1}^{*}(k)=\varnothing$ since $S_{1}\left(x_{1}, x_{1}, k\right)=0, \forall x_{1} \in X$. 
1) Let us show that if $X$ is bounded, then $X_{1}^{*}(k)=X$ for $k$ high enough.

In $\mathbb{R}^{n}$ all the norms are equivalent, thus there exist $\gamma_{1}>0$ and $\gamma_{2}>0$ such that $\gamma_{1}\|x\|_{\text {eucl }} \leq\|x\| \leq \gamma_{2}\|x\|_{\text {eucl }}$ for every $x \in \mathbb{R}^{n}$.

According to (8),

$$
\int_{\Omega_{2}\left(x_{1}, x_{2}, k\right)} f(a) d a \leq \int_{B\left(x_{2} ; \frac{\left\|x_{1}-x_{2}\right\|}{k-1}\right)} f(a) d a
$$

and $\left\|x_{2}-a\right\|<\frac{\left\|x_{1}-x_{2}\right\|}{k-1} \Rightarrow\left\|x_{2}-a\right\|_{\text {eucl }}<\frac{\delta}{k-1}\left\|x_{1}-x_{2}\right\|_{\text {eucl }}$ where $\delta=\frac{\gamma_{2}}{\gamma_{1}}$.

Thus

$$
\begin{gathered}
\int_{\Omega_{2}\left(x_{1}, x_{2}, k\right)} f(a) d a \leq \int_{B\left(x_{2} ; \frac{\left\|x_{1}-x_{2}\right\|}{k-1}\right)} f(a) d a \leq \int_{B_{\text {eucl }}\left(x_{2} ; \frac{\delta}{k-1}\left\|x_{1}-x_{2}\right\|_{\text {eucl }}\right)} f(a) d a \\
\leq \operatorname{vol}\left(B_{\text {eucl }}\left(x_{2} ; \frac{\delta}{k-1}\left\|x_{1}-x_{2}\right\|_{\text {eucl }}\right)\right) \cdot \max _{K} f \leq \operatorname{const.~}\left(\frac{\delta}{k-1}\left\|x_{1}-x_{2}\right\|_{\text {eucl }}\right)^{n} \leq \operatorname{const}\left(\frac{1}{k-1}\right)^{n}
\end{gathered}
$$

uniformly in $x_{1}, x_{2}$ (because $X$ is bounded).

where $\lim _{k \rightarrow \infty}\left(\frac{1}{k-1}\right)^{n}=0$

thus for $k$ high enough $\int_{\Omega_{2}\left(x_{1}, x_{2}, k\right)} f(a) d a<\frac{1}{2}$ for all $x_{1} \in X, x_{2} \in X$, i.e. $X_{1}^{*}(k)=X$.

2) We show now that $X_{1}^{*}(k)$ is not empty for $k$ high enough, even if $X$ is unbounded.

- According to (8), we know that $a \in \Omega_{2}\left(x_{1}, x_{2}, k\right) \Rightarrow\left\|x_{2}-a\right\|<\frac{1}{k-1}\left\|x_{1}-x_{2}\right\|$, i.e. $\Omega_{2}\left(x_{1}, x_{2}, k\right) \subset B\left(x_{2} ; \frac{\left\|x_{1}-x_{2}\right\|}{k-1}\right)$.

- If $a \in \Omega_{2}\left(x_{1}, x_{2}, k\right),\left\|x_{1}-x_{2}\right\| \leq\left\|x_{1}-a\right\|+\left\|a-x_{2}\right\|<\left\|x_{1}-a\right\|+\frac{1}{k-1}\left\|x_{1}-x_{2}\right\|$ thus $\left\|x_{1}-a\right\| \geq\left(1-\frac{1}{k-1}\right)\left\|x_{1}-x_{2}\right\|=\left(\frac{k-2}{k-1}\right)\left\|x_{1}-x_{2}\right\|$

It means that $\left\|x_{1}-a\right\|<\left(\frac{k-2}{k-1}\right)\left\|x_{1}-x_{2}\right\| \Rightarrow a \in \Omega_{1}\left(x_{1}, x_{2}, k\right)$

i.e. $\Omega_{1}\left(x_{1}, x_{2}, k\right) \supset B\left(x_{1} ; \frac{(k-2)\left\|x_{1}-x_{2}\right\|}{k-1}\right)$ if $k>2$.

- Let us fix $x_{1} \in X$, and assume that $k>3$.

There exists $\eta>0$ such that $\int_{B\left(x_{1} ; \eta\right)} f(a) d a>\frac{1}{2}$

- If $\left\|x_{1}-x_{2}\right\|>2 \eta$, then

$\frac{(k-2)}{k-1}\left\|x_{1}-x_{2}\right\| \geq \frac{1}{2}\left\|x_{1}-x_{2}\right\|>\eta$, thus $v_{1}\left(x_{1} ; x_{2}\right)>\frac{1}{2}$, i.e. candidate 2 loses the election if $\left\|x_{1}-x_{2}\right\|>2 \eta$.

- If $\left\|x_{1}-x_{2}\right\| \leq 2 \eta$, then

$v_{2}\left(x_{1} ; x_{2}\right) \leq M \cdot C_{n}\left(\frac{\delta\left\|x_{1}-x_{2}\right\|}{k-1}\right)^{n} \leq M \cdot C_{n}\left(\frac{2 \delta \eta}{k-1}\right)^{n}<\frac{1}{2}$ if $k$ is high enough, where $M=\sup _{a \in X}|f(a)|$ and $C_{n}>0$

i.e. candidate 2 loses the election if $\left\|x_{1}-x_{2}\right\| \leq 2 \eta$, and $k$ sufficiently high . 
This proposition proves that an equilibrium does not always exist in our general framework but existence is guaranteed in a broader range of cases than in the symmetrical model. In that sense, our model is a real generalization of the symmetrical model.

Proposition 6 If the distribution $f$ admits a Condorcet winner, then $k^{*}(f)=1$.

Proof. If there is a Condorcet winner $x_{0}$, it means that, when $k=1$ :

$v_{1}\left(x_{0}, x_{0}\right)=\frac{1}{2}$ and $v_{1}\left(x_{0}, x\right)=0$ for all $x \neq x_{0}$.

If $k>1$, it is clear that $v_{1}\left(x_{0}, x_{0}\right)=1$, and $v_{1}\left(x_{0}, x\right)=0$ as well for $x \neq x_{0}$.

If the policy space is unidimensional, we have $k^{*}(f)=1$ since there is always a Condorcet winner $x_{0}$ in dimension 1. ( $x_{0}$ is defined by $\int_{-\infty}^{x_{0}} f(a) d a=\frac{1}{2}$ ).

Let us assume moreover that $f$ is a uniform distribution on an compact interval $X$, say $X=[0 ; 1]$. Then we can easily show that $\left.X_{1}^{*}=\right] 1-\left(\frac{1+k}{4}\right) ; \frac{k+1}{4}[$ if $1<k \leq 3$, and $X_{1}^{*}=X$ if $k>3$. It means that for a uniform distribution on an interval, we have $k^{* *}(f)=3$.

Getting an explicit form for $k^{*}(f)$ and $k^{* *}(f)$ remains an open question when the dimension of the policy space is higher than 1 .

\subsection{A model with status quo}

We examine an alternative model, where valence measures the capacity to efficiently implement a policy change ${ }^{5}$. More precisely, we assume that there exists a status quo $q$, with $q \in \mathbb{R}^{n}$. If the elected candidate $j$ applies a policy platform $x_{j}$ different from the status quo $q$, this creates temporal disturbances, disorder, inconveniences, even if finally $x_{j}$ is preferred by most voters. The utility of a voter $i$, if candidate $j$ is elected, can be specified the following way:

$$
u\left(\theta_{j}, x_{j}, a_{i}, q\right)=-\left\|x_{j}-a_{i}\right\|-\frac{1}{\theta_{j}}\left\|x_{j}-q\right\|
$$

where $x_{j}, \theta_{j}$ are respectively the policy platform and the valence of candidate $j, a_{i}$ is the bliss point of voter $i$, and $q$ is the status quo. In Equation (10), $\left\|x_{j}-a_{i}\right\|$ is

\footnotetext{
${ }^{5}$ We would like to thank an anonymous referee for suggesting this alternative specification.
} 
the classical downsian distance between the bliss point of the voter and the applied policy, $\frac{1}{\theta_{j}}\left\|x_{j}-q\right\|$ measures the pure inconvenience coming from a policy change. It increases with the importance of change $\left\|x_{j}-q\right\|$, but is lower if candidate $j$ 's valence $\theta_{j}$ is high, which means that he is able to implement efficiently a policy change.

The support of candidate 2 becomes:

$$
\begin{aligned}
& \Omega_{2}\left(x_{1}, x_{2}, \theta_{1}, \theta_{2}, q\right)=\left\{a \in \mathbb{R}^{n} ; u\left(\theta_{2}, x_{2}, a, q\right)>u\left(\theta_{1}, x_{1}, a, q\right)\right\} \\
& =\left\{a \in \mathbb{R}^{n} ;-\left\|x_{2}-a\right\|-\frac{1}{\theta_{2}}\left\|x_{2}-q\right\|>-\left\|x_{1}-a\right\|-\frac{1}{\theta_{1}}\left\|x_{1}-q\right\|\right\} \\
& =\left\{a \in \mathbb{R}^{n} ;\left\|x_{1}-a\right\|>\left\|x_{2}-a\right\|+b\right\}=\Omega_{2}^{a d}\left(x_{1}, x_{2}, b\right)
\end{aligned}
$$

where $b=\frac{1}{\theta_{2}}\left\|x_{2}-q\right\|-\frac{1}{\theta_{1}}\left\|x_{1}-q\right\|$

$\Omega_{2}\left(x_{1}, x_{2}, \theta_{1}, \theta_{2}, q\right)$ is then equal to the support $\Omega_{2}^{a d}\left(x_{1}, x_{2}, b\right)$ of candidate 2 in the additive case, with the additive valence bias $b$. A similar result is true for candidate 1. Proposition 1 becomes:

Proposition 7 (i) $\Omega_{2}\left(x_{1}, x_{2}, \theta_{1}, \theta_{2}, q\right)=\varnothing$ if $b \geq\left\|x_{2}-x_{1}\right\|$

(ii) $\Omega_{2}\left(x_{1}, x_{2}, \theta_{1}, \theta_{2}, q\right)$ and $\Omega_{2}\left(x_{1}, x_{2}, \theta_{1}, \theta_{2}, q\right)$ are unbounded if $-\left\|x_{2}-x_{1}\right\|<$ $b<\left\|x_{2}-x_{1}\right\|$

(iii) $\Omega_{2}\left(x_{1}, x_{2}, \theta_{1}, \theta_{2}, q\right)=\mathbb{R}^{n}$ if $b \leq-\left\|x_{2}-x_{1}\right\|$

where $b=\frac{1}{\theta_{2}}\left\|x_{2}-q\right\|-\frac{1}{\theta_{1}}\left\|x_{1}-q\right\|$

Proof. Straightforward, applying Proposition 1 to $\Omega_{2}^{a d}\left(x_{1}, x_{2}, b\right)$.

If we assume that candidate 1 has a valence advantage, i.e. that $\theta_{1}>\theta_{2}$, then we can define the set $X_{1}^{*}$ as in Equation (9). Proposition 4 is still valid in this model with status quo, since $v_{1}\left(x_{2}, x_{2}\right)=1$ again.

\section{Conclusion}

Further research may deepen our understanding of the logic of valence advantages and the role they play in elections. The multiplicative model yields a fresh look at the existing literature on spatial models of voting. It highlights the role of the extremes. Since extreme voters are far from the center, they are mainly concerned with 
the valence dimension. Even if extreme voters have very different position on the policy space, they have almost identical preferences concerning candidates. On the contrary, for more centrist voters, the impact of announced platforms dominates the valence effect. It then appears that moving from the additive to the multiplicative case has dramatic consequences on the behavior of the electorate.

\section{References}

[1] Alesina, A. et H. Rosenthal (1995), Partisan Politics, Divided Government, and the Economy, Cambridge U.K. : Cambridge University.

[2] Ashworth, Scott, and Ethan Bueno de Mesquita (2005), Valence Competition and Platform Divergence, Princeton University workingpaper

[3] Ansolabehere, Stephen and James Snyder (2000), "Valence politics and equilibrium in spatial election models", Public Choice, vol 103-4, pp 327-336

[4] Banks, J. (1990), "A model of electoral competition with incomplete information" Journal of Economic Theory, vol. 50-2 pp 309-325.

[5] Carrillo, Juan D. and Castanheira, Micael (2002), "Platform Divergence, Political Efficiency and the Median Voter Theorem" CEPR Discussion Paper No3180

[6] Carrillo, Juan D. and Castanheira, Micael (2006), "Information and Strategic Political Polarization", forthcoming in Economic Journal

[7] Dix, M. and Santore, R. (2002), "Candidate ability and platform choice", Economics Letters, vol. 76(2), pp 189-194

[8] Downs, A. (1957), An Economic Theory of Democracy, New York Harper and Row.

[9] Erikson, R. and T. Palfrey (2000), "Equilibria in Campaign Spending Games: Theory and Data," American Political Science Review,vol. 94(3), pp 559-609 
[10] Groseclose, Tim (2001), "A model of candidate location when one candidate has a valence advantage", American Journal of Political Science, vol 45-4, pp 862-886.

[11] Herrera, H, Levine D. and C. Martinelli (2007), "Policy Platforms, Campaign Spending and Voter Participation," , Journal of Public Economics, forthcoming

[12] Lewis-Beck, M. (1988), Economics and elections, Ann Arbor.

[13] Meirowitz, Adam (2005), "Models of Electoral Contests", Princeton University discussion paper.

[14] Mueller, D. C. (ed) (1997), Perspectives on Public Choice, Cambridge U.K. : Cambridge University Press

[15] Mussa, M and S. Rosen (1978), "Monopoly and product quality", Journal of Economic Theory, vol. 18, pp 301-317.

[16] Osborne, M. (1995), "Spatial models of political competition under plurality rule: a survey of some explanations of the number of candidates and the position they take" Canadian Journal of Economics, 28-2, pp 261-301.

[17] Plott, C. (1967), "A notion of equilibrium and its possibility under majority rule" American Economic Review, vol. 57, pp 787-806.

[18] Poole, K. et H. Rosenthal (1984) "US presidential elections 1968-1980: A spatial analysis" American Journal of Political Science, vol. 28, pp 282-312.

[19] Sahuguet, N. and Persico N. (2006), "Campaign spending regulation in a model of redistributive politics," Economic Theory, vol 28, pp 95-124

[20] Wiseman, A. (2005), "A Theory of Partisan Support and Entry Deterrence in Electoral Competition." Journal of Theoretical Politics, vol 18(2), pp123-158

[21] Wittman, D. (1977), "Candidate with policy preferences: A dynamic model" Journal of Economic Theory, vol. 14, pp 180-189. 
[22] Wittman, D. (1990), "Spatial strategies when candidates have policy preferences" in M. Enelow J. Hinich (eds) Advances in the spatial theory of voting Cambridge U.K. : Cambridge University Press pp 66-98.

[23] Zakharov A.V. (2005), "Candidate location and endogenous valence", working paper EERC Moscow

\section{Appendix}

\section{Proof of Proposition 2.}

$$
a \in \Omega_{2} \Leftrightarrow\left\|x_{1}-a\right\|^{2}>k^{2}\left\|x_{2}-a\right\|^{2}
$$

Recalling the property of the Euclidean inner product,

$$
\begin{aligned}
\left\langle x_{1}-a, x_{1}-a\right\rangle=\left\|x_{1}\right\|^{2}-2\left\langle x_{1}, a\right\rangle+\|a\|^{2}, \text { we obtain: } & \\
\left\|x_{1}\right\|^{2}-2\left\langle x_{1}, a\right\rangle+\|a\|^{2} & >k^{2}\left(\left\|x_{2}\right\|^{2}-2\left\langle x_{2}, a\right\rangle+\|a\|^{2}\right) \\
\left(k^{2}-1\right)\|a\|^{2}-2\left\langle a, k^{2} x_{2}-x_{1}\right\rangle & <\left\|x_{1}\right\|^{2}-k^{2}\left\|x_{2}\right\|^{2} \\
\|a\|^{2}-2\left\langle a, \frac{k^{2} x_{2}-x_{1}}{k^{2}-1}\right\rangle & <\frac{\left\|x_{1}\right\|^{2}-k^{2}\left\|x_{2}\right\|^{2}}{k^{2}-1} \\
\left\|a-\left(\frac{k^{2} x_{2}-x_{1}}{k^{2}-1}\right)\right\|^{2} & <\frac{\left\|x_{1}\right\|^{2}-k^{2}\left\|x_{2}\right\|^{2}}{k^{2}-1}+\frac{\left\|k^{2} x_{2}-x_{1}\right\|^{2}}{\left(k^{2}-1\right)^{2}}
\end{aligned}
$$

i.e.

$$
\|a-c\|^{2}<r^{2}
$$

Thus $\Omega_{2}$ is a ball of center $c$, radius $r$. Moreover we have

$$
c=\frac{k^{2} x_{2}-x_{1}}{k^{2}-1}
$$

and

$$
\begin{aligned}
r^{2} & =\frac{\left\|x_{1}\right\|^{2}-k^{2}\left\|x_{2}\right\|^{2}}{k^{2}-1}+\frac{\left\|k^{2} x_{2}-x_{1}\right\|^{2}}{\left(k^{2}-1\right)^{2}} \\
& =\frac{1}{\left(k^{2}-1\right)^{2}}\left[\left(\left\|x_{1}\right\|^{2}-k^{2}\left\|x_{2}\right\|^{2}\right)\left(k^{2}-1\right)+\left\|k^{2} x_{2}\right\|^{2}+\left\|x_{1}\right\|^{2}-2 k^{2}\left\langle x_{1}, x_{2}\right\rangle\right] \\
& =\frac{1}{\left(k^{2}-1\right)^{2}}\left[k^{2}\left\|x_{1}\right\|^{2}+k^{2}\left\|x_{2}\right\|^{2}-2 k^{2}\left\langle x_{1}, x_{2}\right\rangle\right] \\
& =\frac{k^{2}}{\left(k^{2}-1\right)^{2}}\left\|x_{1}-x_{2}\right\|^{2}
\end{aligned}
$$


Finally:

$$
\begin{aligned}
& c=-\beta x_{1}+(1+\beta) x_{2} \text { where } \beta=\frac{1}{k^{2}-1}>0 \\
& r=\frac{k}{k^{2}-1}\left\|x_{1}-x_{2}\right\|
\end{aligned}
$$

Moreover, $\sin \alpha=\frac{r}{\left\|x_{1}-c\right\|}=\frac{\frac{k}{k^{2}-1}\left\|x_{2}-x_{1}\right\|}{\left\|\frac{k^{2} x_{2}-x_{1}}{k^{2}-1}-x_{1}\right\|}=\frac{\frac{k}{k^{2}-1}\left\|x_{2}-x_{1}\right\|}{\left\|\frac{k^{2} x_{2}-x_{1}-\left(k^{2}-1\right) x_{1}}{k^{2}-1}\right\|}=\frac{k\left\|x_{2}-x_{1}\right\|}{\left\|k^{2} x_{2}-k^{2} x_{1}\right\|}=\frac{k}{k^{2}}=\frac{1}{k}$

This concludes the proof.

\section{Proof of Proposition 3.}

- First, we prove that $X_{1}^{*}$ is a open set.

Clearly $\left(x_{1}, x_{2}\right) \mapsto S_{2}\left(x_{1}, x_{2}, k\right)$ is a continuous function on the compact set $X \times X$.

$$
x_{1} \in X_{1}^{*} \Leftrightarrow \forall x_{2} \in X, S_{2}\left(x_{1}, x_{2}, k\right)<\frac{1}{2}
$$

and as $S_{2}$ must be uniformly continuous on the compact set $X \times X$ :

$$
x_{1} \in X_{1}^{*} \Leftrightarrow \exists \gamma>0, \forall x_{2} \in X, S_{2}\left(x_{1}, x_{2}, k\right)<\frac{1}{2}-\gamma
$$

For any $\varepsilon>0$, let $x_{1}^{\prime} \in X$, such that $\left\|x_{1}-x_{1}^{\prime}\right\|<\varepsilon$

We want to show for all $x_{2} \in X$ that $S_{2}\left(x_{1}^{\prime}, x_{2}, k\right)<\frac{1}{2}$, i.e. that $\int_{\Omega_{2}\left(x_{1}^{\prime}, x_{2}, k\right)} f(a) d a<$ $\frac{1}{2}$

We have $\int_{\Omega_{2}\left(x_{1}, x_{2}, k\right)} f(a) d a<\frac{1}{2}-\gamma$ for every $x_{2} \in X$.

$$
\begin{aligned}
& \int_{\Omega_{2}\left(x_{1}^{\prime}, x_{2}, k\right)} f(a) d a \leq \int_{\Omega_{2}\left(x_{1}, x_{2}, k\right)} f(a) d a+\int_{\Omega_{2}\left(x_{1}^{\prime}, x_{2}, k\right) \backslash \Omega_{2}\left(x_{1}, x_{2}, k\right)} f(a) d a \\
& <\frac{1}{2}-\gamma+\int_{\Omega_{2}\left(x_{1}^{\prime}, x_{2}, k\right) \backslash \Omega_{2}\left(x_{1}, x_{2}, k\right)} f(a) d a
\end{aligned}
$$

We must show that $\int_{\Omega_{2}\left(x_{1}^{\prime}, x_{2}, k\right) \backslash \Omega_{2}\left(x_{1}, x_{2}, k\right)} f(a) d a<\gamma$ for all $x_{2} \in X$, if $\varepsilon$ is small enough.

According to Proposition $2, \Omega_{2}\left(x_{1}^{\prime}, x_{2}, k\right)$ and $\Omega_{2}\left(x_{1}, x_{2}, k\right)$ are balls in $\mathbb{R}^{n}$, i.e. $\Omega_{2}\left(x_{1}^{\prime}, x_{2}, k\right)=B\left(c^{\prime}, r^{\prime}\right)$ and $\Omega_{2}\left(x_{1}, x_{2}, k\right)=B(c, r)$.

$$
\begin{aligned}
& \int_{\Omega_{2}\left(x_{1}^{\prime}, x_{2}, k\right) \backslash \Omega_{2}\left(x_{1}, x_{2}, k\right)} f(a) d a \leq \operatorname{M.vol}\left(\Omega_{2}\left(x_{1}^{\prime}, x_{2}, k\right) \backslash \Omega_{2}\left(x_{1}, x_{2}, k\right)\right) \\
& =\operatorname{M.vol}\left(B\left(c^{\prime}, r^{\prime}\right)-B(c, r)\right) \\
& \leq M \cdot \operatorname{vol}\left(B\left(c^{\prime}, r^{\prime}\right)-B\left(c^{\prime}, r\right)\right)+M \cdot \operatorname{vol}\left(B\left(c^{\prime}, r\right)-B(c, r)\right) \\
& \leq \text { M.const. }\left(r^{\prime n}-r^{n}\right)+M \cdot r^{n}\left\|c^{\prime}-c\right\| \\
& \leq \operatorname{const}\left(\left\|x_{1}^{\prime}-x_{2}\right\|^{n}-\left\|x_{1}-x_{2}\right\|^{n}\right)+\text { const. } \varepsilon .\left\|x_{1}-x_{2}\right\|^{n} \leq \varepsilon \text {.const, which is }
\end{aligned}
$$

lower than $\gamma$, if $\varepsilon$ is small enough.

Consequently, $X_{1}^{*}(k)$ is an open set. 
- Let us now turn to the convexity problem.

Consider $x \in X_{1}^{*}$ and $y \in X_{1}^{*}$, and a point $z \in[x, y]$. We want to show that $z \in X_{1}^{*}$, i.e. that $S_{2}\left(z, x_{2}\right)<\frac{1}{2}$, for any $x_{2} \in X$.

Let $x_{2} \in X$ be given.

$\Omega_{2}\left(z, x_{2}\right)$ is a ball of center $c_{0}=c\left(z, x_{2}\right)=-\beta z+(1+\beta) x_{2}$,

and of radius $r_{0}=\frac{k}{k^{2}-1}\left\|z-x_{2}\right\|=\frac{1}{k}\left\|(1+\beta)\left(z-x_{2}\right)\right\|=\frac{1}{k}\left\|z+\beta z-(1+\beta) x_{2}\right\|$

Let $x_{2}^{\prime}=\frac{1}{1+\beta}\left(-\beta(z-x)+(1+\beta) x_{2}\right)$ and $x^{\prime \prime}{ }_{2}=\frac{1}{1+\beta}\left(-\beta(z-y)+(1+\beta) x_{2}\right)$ $\Omega_{2}\left(x, x_{2}^{\prime}\right)$ is a ball of center $c\left(x, x_{2}^{\prime}\right)=-\beta x+(1+\beta) x_{2}^{\prime}=-\beta x-\beta(z-x)+(1+\beta) x_{2}$

$$
=-\beta z+(1+\beta) x_{2}=c_{0}
$$

and radius $r^{\prime}=\frac{k}{k^{2}-1}\left\|x-x_{2}^{\prime}\right\|=\frac{1+\beta}{k}\left\|x-x_{2}^{\prime}\right\|$ since $\beta=\frac{1}{k^{2}-1}$

$$
r^{\prime}=\frac{1}{k}\left\|(1+\beta) x+\beta(z-x)-(1+\beta) x_{2}\right\|=\frac{1}{k}\left\|x+\beta z-(1+\beta) x_{2}\right\|
$$

$\Omega_{2}\left(y, x_{2}\right)$ is a ball of center $c\left(y, x_{2}\right)=-\beta y+(1+\beta) x_{2}$

$$
=-\beta y-\beta(z-y)+(1+\beta) x_{2}=-\beta z+(1+\beta) x_{2}=c_{0}
$$

and radius $r "=\frac{k}{k^{2}-1}\left\|y-x{ }_{2}\right\|=\frac{1+\beta}{k}\left\|y-x{ }_{2}\right\|$

$$
r "=\frac{1}{k}\left\|(1+\beta) y+\beta(z-y)-(1+\beta) x_{2}\right\|=\frac{1}{k}\left\|y+\beta z-(1+\beta) x_{2}\right\|
$$

$\Omega_{2}\left(z, x_{2}\right), \Omega_{2}\left(x, x_{2}^{\prime}\right)$ and $\Omega_{2}\left(y, x_{2}\right)$ have the same center, and have radius $r_{0}, r^{\prime}$ and $r$ "respectively.

$t \mapsto\left\|t+\beta z-(1+\beta) x_{2}\right\|$ is a convex function, so $r_{0} \leq \max \left(r^{\prime}, r^{\prime \prime}\right)$,

i.e. $\Omega_{2}\left(z, x_{2}\right) \subseteq \Omega_{2}\left(x, x_{2}^{\prime}\right)$ or $\Omega_{2}\left(z, x_{2}\right) \subseteq \Omega_{2}\left(y, x_{2}\right)$.

thus $S_{2}\left(z, x_{2}\right) \leq \max \left(S_{2}\left(x, x_{2}^{\prime}\right), S_{2}\left(y, x_{2}\right)\right)<\frac{1}{2}$.

This is true for any $x_{2} \in X$, so that $z \in X_{1}^{*}$ 